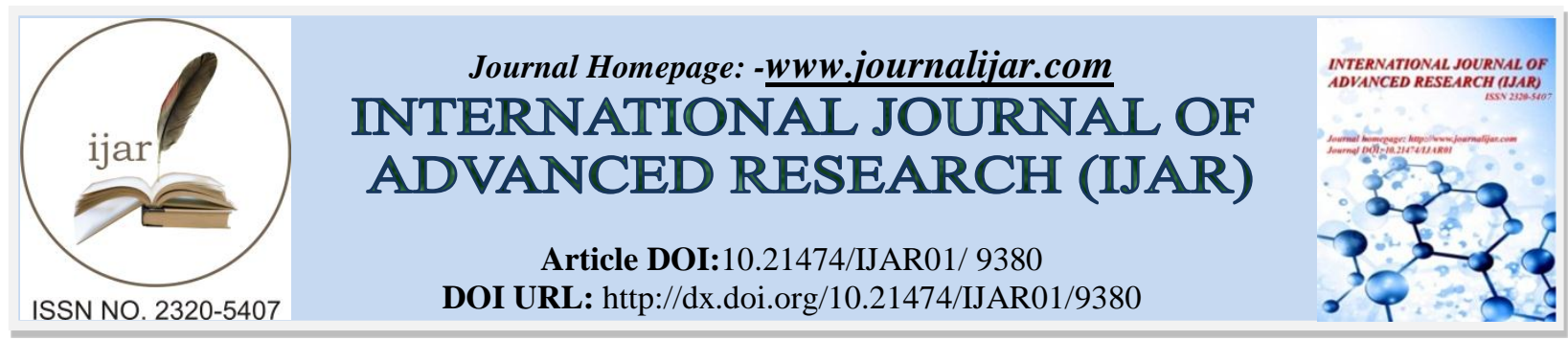

RESEARCH ARTICLE

\title{
ESTIMATION OF ELLAGIC ACID IN AYURVEDIC POLYHERBAL FORMULATION AMRTOTTARA KVATHA BY HPTLC METHOD.
}

\section{Dr. R.S.Karthika ${ }^{1}$, Dr. A.Shahul Hameed ${ }^{2}$ And M.T. Meenu ${ }^{3}$.}

1. MD Scholar, Department of Dravyagunavijnana, Govt. Ayurveda College, Trivandrum.

2. Professor, Department of Dravyagunavijnana, Govt. Ayurveda College, Trivandrum.

3. Senior Research Fellow, CSIR-NIIST, Trivandrum.

\section{Manuscript Info}

\section{Manuscript History}

Received: 10 May 2019

Final Accepted: 12 June 2019

Published: July 2019

Key words:-

polyherbal formulation, Amrtottara kvatha, Ellagic acid, HPTLC.

\begin{abstract}
Amrtottara kvatha is a decoction which is used primarily in the management of hyperpyrexia (jwara). Specific plant parts of Tinospora cordifolia (Willd.) Miers.,Terminalia chebula Retz., and Zingiber offficinale Roscoe. are its ingredients. Only nine compounds have been reported from this polyherbal formulation. In the current study a simple and precise high performance thin layer chromatographic (HPTLC) method was developed for identification and quantification of an unreported compound Ellagic acid in this decoction. Ellagic acid is one of the major compounds in Terminalia chebula Retz. The HPTLC method used aluminium plates pre-coated with silica gel $60_{\mathrm{F} 254}$ as the stationary phase and Toluene: Methanol: Ethyl acetate: Formic acid (4:1:4:1, v/v) as solvent system. This system gave compact spot for Ellagic acid (Rf: $0.39 \pm 0.0038$ ). The method was validated for specificity, linearity and precision. The limit of detection and quantification were $0.52 \mathrm{ng}$ and $1.577 \mathrm{ng}$ respectively. The amount of Ellagic acid in Amrtottara kvatha was estimated as $0.050 \pm 0.016 \% \mathrm{w} / \mathrm{w}$ by the developed method. The method for identification and quantification of Ellagic acid in Amrtottara kvatha can be used in pharmacological exploration and standardization of Amrtottara kvatha.
\end{abstract}

Copy Right, IJAR, 2019,. All rights reserved.

\section{Introduction:-}

Amrtottara kvatha is one of the widely used Ayurvedic preparations, and is primarily indicated for jwara (hyperpyrexia). The drugs used in the preparation of this decoction are, fresh stem of Tinospora cordifolia (Willd.) Miers (Guduchi), dried fruit rind of Terminalia chebula Retz. (Haritaki) and dried rhizome of Zingiber offficinale Roscoe. (Shunti) in the ratio 3:2:1("Chikitsamanjari”, 2015, p.58), ("Ayurvedic formulary of India", 2003, p.53), ("Sahasrayogam", 2006, p.4) .The individual ingredients of this formulation have been studied extensively, especially for their phytochemistry and biological activities. But, available research data regarding this formulation as such is very little. Only nine compounds have been so far reported in Amrtottara kvatha. They are Gallic acid, Chebulic acid, Quinic acid, Tartaric acid, Protocatechuic acid-4-glucoside, Caffeoyl glucose, Quercetin, Quercetin3-glucuronide and Quercetin rhamnoside (Sulaiman C.T. \& Indira Balachandran, 2014).

Corresponding Author:-Dr. A.Shahul Hameed.

Address:-Professor, Department of Dravyagunavijnana, Govt. Ayurveda College, Trivandrum. 
The determination of phytochemical composition of a drug may help in understanding its mode of action, and also serve as a method for standardisation.

In phytochemical analysis of this decoction, Ellagic acid, one of the major constituents of fruit of Terminalia chebula was found to be present in a qualitative thin layer chrmomatographic (TLC) study. Thus it was explored further using HPTLC, which is a simple and sensitive analytical technique.The present study aimed to develop a validated HPTLC method to identify and quantify Ellagic acid in Amrtottara kvatha.

\section{Materials and methods:- \\ Materials: \\ Ellagic acid:}

The compound Ellagic acid was isolated from acetone extract of Haritaki (Terminalia chebula) using repeated gravitational column chromatography, and characterized using nuclear magnetic resonance (NMR) and high resolution mass spectrometry (HRMS) analysis. This was used as standard for analysis.

\section{Amrtottara kvatha:}

The decoction Amrtottara kvatha (AMK) was prepared in laboratory according to standard procedure (Sharngadhara n.d., p. 71). The raw drugs for its preparation was procured from botanical garden, Govt. Ayurveda College Trivandrum (Tinospora cordifolia), Govt. Agricultural College, Vellayani (Zingiber officinale) and natural habitat from Kottoor, Trivandrum (Terminalia chebula). These were authenticated by botanist at Pharmacognosy unit, Govt. Ayurveda College Trivandrum.

\section{Reagents:}

HPLC grade solvents from Merk, Germany were used.

\section{Instruments and equipment used:}

High Performance Thin Layer Chromatograph (CAMAG, Switzerland) system, Linomat V sample applicator, photo documentation chamber (CAMAG Reprostar 3) with dual wavelength UV lamp (254 nm and $366 \mathrm{~nm}$ ), CAMAG twin-trough chambers, CAMAG TLC scanner III , controlled by WINCATS software 1.3.4 version, analytical balance, and air blower.

\section{Methods:}

Preparation of standard solution:

Stock solution of Ellagic acid $(0.11 \mathrm{mg} / \mathrm{ml})$ was prepared by dissolving $11 \mathrm{mg}$ of accurately weighed standard in 100 $\mathrm{ml}$ of methanol.

\section{Preparation of AMK:}

$3 \mathrm{~g}$ of cut and crushed fresh stem of Tinospora cordifolia (Guduchi), $2 \mathrm{~g}$ of coarsely powdered dried fruit rind of Terminalia chebula (Haritaki) and $1 \mathrm{~g}$ of coarsely powdered dried rhizome of Zingiber officinale (Shunti) were mixed together and boiled in $96 \mathrm{ml}$ water, and reduced to $12 \mathrm{ml}$ and strained through a clean cotton cloth (4 layered).

\section{Extraction of Ellagic acid from AMK:}

$10 \mathrm{ml}$ of this decoction was taken in a beaker and kept on water bath maintained at $80{ }^{\circ} \mathrm{C}$ for about 2 hours until a dry residue was obtained. The residue was dissolved in $10 \mathrm{ml}$ methanol by continuously stirring with a glass rod for 20 minutes. The undissolved portion was filtered off through Whatman no.1 filter paper, and the clear solution was made up to $10 \mathrm{ml}$ in a volumetric flask. This was used for quantification.

\section{Chromatographic conditions:}

Chromatographic separation was achieved on HPTLC plates $(10 \times 10 \mathrm{~cm})$ pre-coated with silica gel $60 \mathrm{~F}_{254}$ of 0.2 $\mathrm{mm}$ thickness with aluminium sheet support. The plates were prewashed with methanol and activated at $110^{\circ} \mathrm{C}$ for 8 minutes prior to application. Standard solutions of Ellagic acid and AMK extract were applied to the plates as bands $6.0 \mathrm{~mm}$ wide, $10.0 \mathrm{~mm}$ from the bottom edge of the same chromatographic plate by using of a Camag (Switzerland) Linomat 5 sample applicator equipped with a $100 \mu 1$ Hamilton syringe. Ascending development to a distance of 70 $\mathrm{mm}$ was performed at room temperature $\left(24 \pm 2^{\circ} \mathrm{C}\right)$ with mobile phase in a Camag glass twin-trough chamber. After development, the plates were dried, viewed at $254 \mathrm{~nm}$ and $366 \mathrm{~nm}$ and photographed. This was followed by 
densitometric scanning with a Camag TLC Scanner 3 using winCATS software. Spectral scanning was done at the wavelength of maximum absorbance.

\section{Optimization of mobile phase:}

The standard stock solution was spotted on to TLC plate and developed in different solvent systems. Many preliminary trials were carried out for selection of mobile phase. Mobile phase composition was optimized to provide accurate, precise and reproducible results for the determination of Ellagic acid.

\section{Quantification:}

For this purpose, six different concentrations of standard and the sample (methanol extract of AMK) were applied on TLC plate simultaneously. The volumes of standard and sample which give a desirable calibration curve was selected for estimation. The volumes of standard used were, $3 \mu 1,5 \mu 1,7 \mu \mathrm{l}, 9 \mu \mathrm{l}, 11 \mu \mathrm{l}, 13 \mu \mathrm{l}$ (i.e., $0.33 \mu \mathrm{g}, 0.55 \mu \mathrm{g}$, $0.77 \mu \mathrm{g}, 0.99 \mu \mathrm{g}, 1.21 \mu \mathrm{g}, 1.43 \mu \mathrm{g}$ ) of standard stock solution. Sample was applied in a volume of $2 \mu 1$. For obtaining calibration curve, densitometric scanning of the plate was performed in absorption mode at the wavelength of maximum absorbance. The wavelength of maximum absorbance was found to be $279 \mathrm{~nm}$ for Ellagic acid. Quantitative data was obtained from the software by fixing the \% deviation to get an appropriate regression line having a desirable standard deviation $(<5)$ and regression coefficient $(<1)$, while including sample spots in the regression line. Percentage weight by weight $(\% \mathrm{w} / \mathrm{w})$ of Ellagic acid in sample was calculated w.r.t to the $\%$ weight of drug in kvatha.

\section{Validation of the HPTLC method: Specificity:}

The specificity of the method was ascertained by applying standard and blank simultaneously on the TLC plate. The spot of Ellagic acid was confirmed by comparing Rf value and spectra of the spot with that of standard. The peak purity of standard was assessed by comparing the spectra at three different levels, i.e. peak start, peak apex and peak end positions of the spot.

\section{Precision:}

Instrumental precision was measured by replicate $(\mathrm{n}=6)$ application of same standard solution.

\section{Linearity:}

Linearity was evaluated by visual inspection of a plot of signals as a function of analyte concentration.

\section{Accuracy:}

It was inferred after precision, linearity and specificity were established.

Detection limit:

Limit of detection $=3.3 \sigma / \mathrm{S}$; where $\sigma=$ the standard deviation, $\mathrm{S}=$ the slope of calibration curve

\section{Quantification limit:}

Limit of quantification $=10 \sigma / \mathrm{S}$

\section{Results:-}

TLC at $254 \mathrm{~nm}$ (Photo documentation):

Under 254 nm, 2 spots were observed for the sample (Figure no. $1 \mathrm{~A}$ )

Densitometric scanning:

Densitometric scanning at $254 \mathrm{~nm}$ gave peaks of Ellagic acid (EA) at an $\mathrm{Rf}$ value $0.39 \pm 0.0038$. The $\mathrm{Rf}$ values of the peaks of Ellagic acid obtained were, EA 1- 0.39, EA 2-0.39, EA 3-0.39, EA 4-0.39, EA 5-0.39, EA 6-0.39, AMK0.40

\section{Spectral comparison of standard and sample (at $279 \mathrm{~nm})$ :}

Based on the initial spectral scanning, the spectral comparison was done at $279 \mathrm{~nm}$, which was the wavelength of maximum absorbance. The spectra of standard and sample were superimposable.

\section{Quantification:}

A linear calibration curve was obtained both via peak area and peak height. The standard deviations and regression coefficients were desirable. Three replicate analysis were done for statistical analysis. The regression equation (via 
peak area), $\mathrm{Y}=1891.7+14.7 \mathrm{X}$ showed a standard deviation of $2.32 \%$ and a regression coefficient 0.9976 (Figure no. $3 \mathrm{C}$ ). The amount of Ellagic acid in sample was calculated based on the quantification of Ellagic acid in the winCATS software, for the respective regression equations. It is expressed as \%w/w of kvatha and given in the following table.

\begin{tabular}{|l|l|}
\hline Sample & $\%$ w/w of Ellagic acid(Mean \pm SD) \\
\hline AMK & $0.050 \pm 0.016$ \\
\hline
\end{tabular}

Table no 1:- $\%$ w/w of Ellagic acid in kvatha sample

Validation studies:

The results of validation studies have been tabulated below (Table no.2)

\begin{tabular}{|c|c|c|c|}
\hline SL no. & Experiment & Observation & Result \\
\hline 1. & Specificity & $\begin{array}{l}\text { Rf of spot both in the standard and the } \\
\text { sample were approximately same, with } \\
\text { an overlapping spectra }\end{array}$ & Specific \\
\hline 2. & Instrumental precision & $\mathrm{Rf}$ of the spots $=0.39 \pm 0.000$ & Precise \\
\hline 3. & Linearity & $\begin{array}{l}\text { Linear calibration curve was obtained } \\
\text { both via height and area }\end{array}$ & Linear \\
\hline 4. & Accuracy & $\begin{array}{l}\text { Inferred to be accurate as it was validated } \\
\text { for precision, linearity and specificity }\end{array}$ & Accurate \\
\hline 5. & Limit of detection & - & $0.52 \mathrm{ng}$ \\
\hline 6. & Limit of quantification & - & $1.577 \mathrm{ng}$ \\
\hline
\end{tabular}

Table no 2:-Results of HPTLC method developed for estimation of Ellagic acid
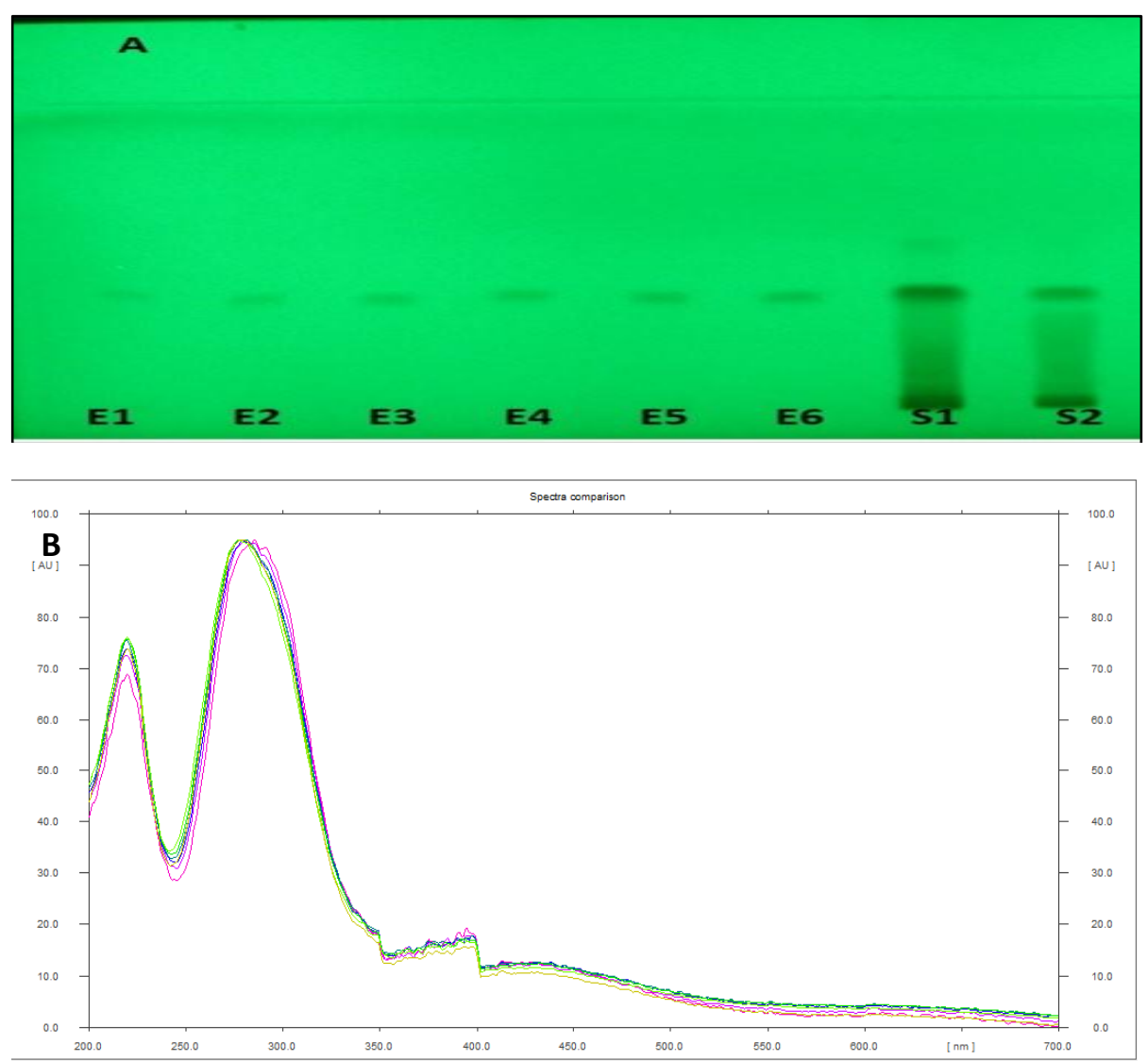

Figure no 1:- A. HPTLC profile of standard and sample at 254nm; E 1-E6: standard Ellagic acid solution in different concentrations; S2: AMK extract, 1B: Spectral comparison of standard Ellagic acid and Ellagic acid quantified from sample 


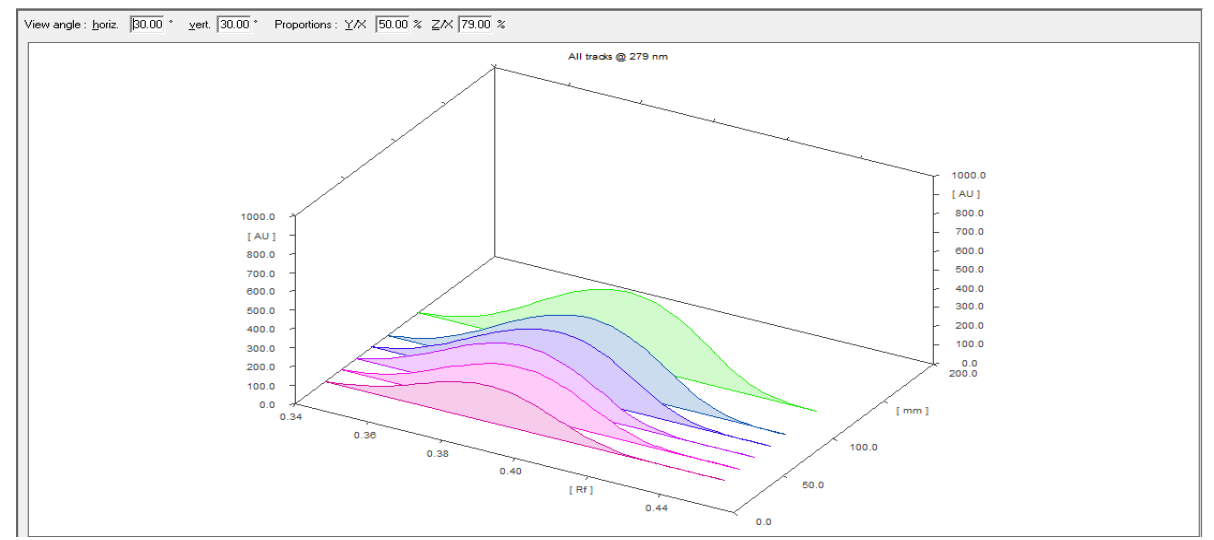

Figure no. 2:- 3D display of chromatogram of standard Ellagic acid and Ellagic acid quantified from sample.
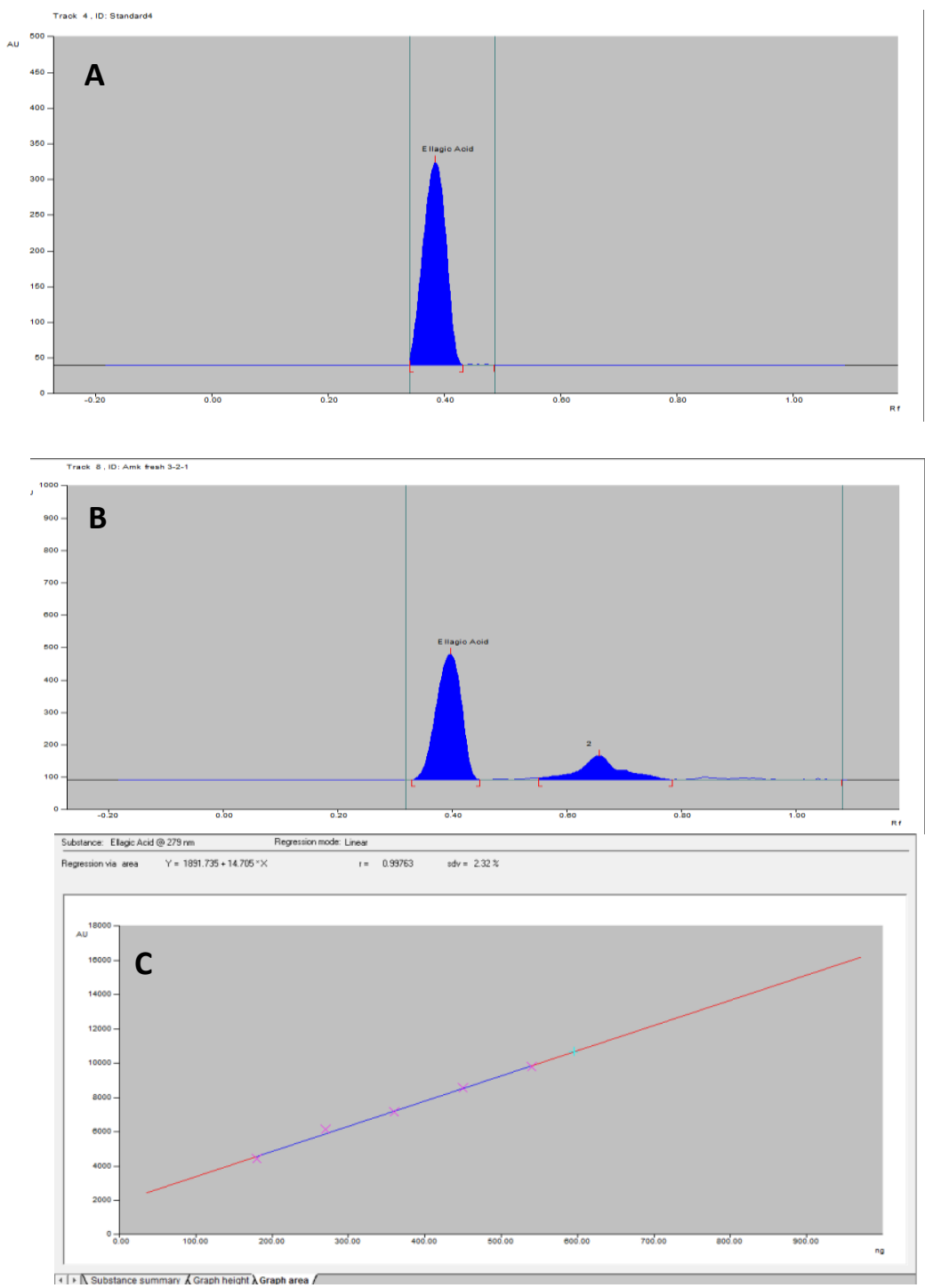

Figure no. 3:-A: Peak display of standard Ellagic acid; 3 B: peak display of AMK extract; 3 C: Calibration plot of Ellagic acid via peak area 


\section{Discussion:-}

The compound Ellagic acid which was one of the major compounds obtained from Terminalia chebula (by column chromatographic isolation) was selected for its determination in Amrtottara kvatha. HPTLC method was selected as it is a widely accepted analytical technique which is simple and highly sensitive. It has the advantage that several samples can be run simultaneously using a small quantity of mobile phase and thus reducing the analysis time and cost. The study developed a validated HPTLC method for analysis of Ellagic acid in Amrtottara kvatha. Ellagic acid is a polyphenol which has varied pharmacological activities like anti-inflammatory, anti-carcinogenic, antimicrobial, and anti-arthritic (Allam.G et al, 2016), (PubChem Database, n.d.). The present study is the first report of Ellagic in Amrtottara kvatha. This may prove to be a remarkable contribution to the existing knowledge, especially in the field of standardization.

\section{Conclusion:-}

The compound Ellagic acid was reported for the first time in Amrtottara kvatha. Thus this study would help to draw the possibility of a significant role of Ellagic acid in this formulation. The HPTLC method developed can be successfully employed for standardization of Amrtottara kvatha and quantitative analysis of Ellagic acid in it.

\section{Acknowledgement:-}

Authors are thankful to Dr. K.V. Radhakrishnan, Senior Principal Scientist, Organic chemistry section, CSIRNIIST, Trivandrum, Mr Mahadevan, Research Assistant, and Dr. Binitha Raj, Research Officer, Drug standardization unit, Government Ayurveda College, Trivandrum.

\section{References:-}

1. Allam G, Mahdi EA, Alzahrani AM, Abuelsaad AS. (2016). Ellagic acid alleviates adjuvant induced arthritis by modulation of pro-and anti-inflammatory cytokines. Central-European journal of immunology, Retrieved, from. Allam G, Mahdi EA, Alzahrani AM, Abuelsaad AS. Ellagic acid alleviates adjuvant induced arthritis by modulation of pro-and anti-inflammatory cytokines. Central-European journal of immunology. 2016; 41(4):339.

2. Ayurvedic formulary of India (Vol. 1). (2007). New Delhi: Ministry of Health and Family welfare.

3. Chikitsamanjari (Sreemannamboothiri trans.). (p. 58). Alappuzha: Vidyarambham publishers.

4. National Centre for Biotechnology Information. PubChem Database. Ellagic acid, CID=5281855, https://pubchem.ncbi.nlm.nih.gov/compound/Ellagic-acid (accessed on July 24, 2019)

5. Sahasrayogam (Nishteswar \& Vaidyanath R trans.) (2006) (2nd ed.P.4). Varanasi: Chowkhamba Sanskrit Series Office.

6. Sharngadhara (G.Prabhakar Rao trans.) (2013). Kvatha kalpana. Sharngadhara samhita (p. 7). New Delhi: Chaukhambha publications.

7. Sulaiman C T \& Balachandran I. (2015). Chemical Profiling of an Indian Herbal Formula Using Liquid Chromatography Coupled with Electro Spray Ionization Mass Spectrometry. Spectroscopy Letters: An International Journal for Rapid Communication, 5-6. Retrieved, from https://www.tandfonline.com/doi/abs/10.1080/00387010.2013.872670. 